\title{
Exploring Students' Difficulties in Solving Application of Integral Problems in Selected Zambian Colleges of Education
}

\author{
Julius Zulu*, Robert Changwe, Mphande Fumbani, Friday Nyimbili, George Mulenga, Donald \\ Chisowa \\ The University of Zambia, School of Education, Department of Mathematics and Science Education, P. O Box \\ 32379, Lusaka, ZAMBIA \\ *Corresponding Author: Julius Zulu, The University of Zambia, School of Education, Department of \\ Mathematics and Science Education, P. O Box 32379, Lusaka, ZAMBIA. Email: julius.zulu@unza.zm
}

\begin{abstract}
The use of integral representation to model and interpret physical experiences and solve applications of integral problems is one of the teaching objectives' in mathematics teacher education curriculum for tertiary institutions of learning in Zambia. The study sought to explore difficulties students' encounter in solving application of integral problems and students' perception and how to improve their skills in solving application of integral calculus problems in Zambian Colleges of Education. One hundred and fifty $(n=150)$ students at three Colleges of Education in Lusaka district of Zambia) had participated. A qualitative study approach, which followed a descriptive case study design was used. Data was collected through the use of semi-structured interviews. Audio recordings were used to capture interviews' in its totality. Thematic analysis was used to analyse data. The factors constraining College of Education students in solving application of integral problems included: difficulties related to the identification of the integral formula to use, difficulties related to understanding of the integral problem i.e. language, use of the given information, and identifying the variables. The study therefore, recommended that lecturers should allocate more time on topics like the application of integral problems, assign translation application of integral problems that cannot be solved by trivial syntactic or other non-operative approaches, emphasize the operative nature of equations, and focus on the development of the integral formulas.
\end{abstract}

Keywords: Calculus, Problem, Integral, Integral problem, Problem Solving

\section{INTRODUCTION}

Calculus is the branch of mathematics that deals with derivatives, infinite series, integrals and limits. The role of calculus in economic analysis cannot be over emphasized. For example, policy economists analyse relationships between variables in order to understand, predict, plan, and influence behaviour among other things. Thus, in order to understand the sophisticated, complex behaviour of economic agents in the marketplace, then, it would be appropriate to model that behaviour using complex, nonlinear functions and then analyse our models appropriately. More simply, real world behaviour is not linear. Therefore, any attempt to understand real economic behaviour requires nonlinear modelling and the appropriate use of calculus. Any other, simpler forms of analysis lack the detail and sophistication essential to creating and evaluating policy. It could be because of this reason that calculus is taught to students not only in Zambia but across the globe. We therefore make an argument in this study that having a calculus informed citizenry is the cornerstone for decision making and promotion of the value chain in citizens.

Despite the importance of calculus, research has shown inadequacies in students' solving application of integral problems (Zulu, 2019). However, in Zambian Colleges of Education, application of integration in real life situation is a topic under calculus which is taught to undergraduate students pursuing related fields such as Bachelor of Science (Bsc.), Bachelor of Science with Education (BSc.Ed), Bachelor of Secondary Education (BSec. Ed), Bachelor of Arts with Education (BA.Ed), and Bachelor of Education Secondary (Mathematics and Science) (BED. MAS) (Zulu\&Nalube, 2019).

Additionally, there are many researchers that are devoted to investigating undergraduate students' competency in the mathematical modelling process. We will highlight some research in this area. A 
measure of attainment for stages of modelling was developed by Haines and Crouch (2001). The authors expanded their study in Crouch and Haines (2004) where they compared undergraduates (novices) and engineering research students (experts). They suggested a three-level classification of the developmental processes which the students pass through in moving from novice behaviour to that of an expert. One of the conclusions of this research was that "students are weak in linking the mathematical world and the real world, thus supporting a view that students need much stronger experiences in building real world mathematical world connections" (Crouch and Haines, 2004: 204).

Furthermore, an investigation of undergraduate students' working styles in a mathematical modelling activity was undertaken by Maull and Berry (2001); whilst a study by Nyman and Berry (2002) investigated the development of transferable skills in undergraduate mathematics students through mathematical modelling. Relationships between students' mathematical competencies and their skills in modelling were considered in Galbraith and Haines (1998) and in Gruenwald and Schott (2000). From the cited studies, it can be argued that there is a link between mathematical modelling and solving application problems. In this study, we support the view that the application of integral problems can be considered as a subset of the mathematical modelling process which can be described as "consisting of structuring, generating real world facts and data, mathematising, working mathematically and interpreting or validating.

Our perception of application problems linked to mathematical modelling process again is similar to what was expressed by Niss, Blum and Galbraith (2007: 23) when they explained that;

\begin{abstract}
Typified by problems like finding the largest cylindrical parcel that can be shipped according to certain postal requirements, standard applications are characterised by the fact that the appropriate model is immediately at hand. Such problems can be solved without further regard to the nature of the given real-world context. In my example, this context can be stripped away easily to expose a purely mathematical question about maximizing volumes of cylinders under prescribed constraints. So, the translation processes involved in solving standard applications are straightforward, that is, again, only a limited subset of the modelling cycle is needed.
\end{abstract}

In this study, we used Mathematical Problem-Solving theory propounded by George Polya (Polya, 1957) to examined students' difficulties when solving application of integral problems with the constructive type of integral problem which requires the carrying out of some calculations and drawing a conclusion from some given information and existing knowledge of mathematics.

Common application problems from a typical first-year university calculus course are normally mathematised to a large extent, so there is no need to collect or analyse the data, make assumptions, and so on. Still, in many application problems in general and integral problems in particular, we have observed that students have to go through the formulation step of mathematical modelling process that often requires choosing or constructing formula or setting up a function for further investigation in order for an application integral problem to be solved. Normally, the information given in an application problem for instance, integral problems includes some numbers, expressions, and stories. This is the stage where many students have difficulties in translating the word problem into the mathematical formula and then deciding which mathematics they should use (Zulu and Nalube, 2019).

As Clement, Lochhead and Monk (1981: 287) pointed out "rather than being an immediate aid in learning mathematics, the process of 'translation' between a practical situation and mathematical notation presents the student with a fresh difficulty that must be overcome if the application (or the mathematics) is to make any sense to the student in the long run" Talking about the nature of that "translation" the scholars further argued that;

What makes teaching (and learning) of these translation skills so difficult is that behind them there are many unarticulated mental processes that guide one in construction of a new equation on paper. These processes are not identical with the symbols; in fact, the symbols themselves, as they appear on the blackboard or in the book, communicate to the student very little about the processes used to produce them. There seems to be no way to explain such translation processes to students quickly. (p. 289). 
In this study we report Colleges of Education students' difficulties in solving a common application of integral problem from a typical first-year mathematics course. We agree with Galbraith, Stillman, Brown, and Edwards (2007: 132) that for such students;

Problems need to be such that the mathematics required for solution is within the range of known and practical knowledge and techniques. It may not be clear however; just which mathematics is appropriate for the job at hand: such decisions are part of the requirements of the modelling process.

Further, we attempt to categorize these students' difficulties in order to try to answer the research question: Why is it that most of the students find it a challenge to use their knowledge to construct a simple function in an application of integral problem amongst College of Education students in a very familiar context? Many researchers and practitioners in different ways ask a similar question. For instance, Crouch \& Haines, (2004: 199) wondered;

Why is it that students of engineering science, technology and allied subjects find it difficult to move freely between the real world and the mathematical world, when by their own choice of applied discipline, one might have expected strong engagement in modelling or pseudo-modelling tasks?

While these studies have provided beneficial information on undergraduate students' competency in the mathematical modelling process, there is still much to be explored about the specific difficulties that limit students' success when solving application of integral problems, which is the motivation for this study. Moreover, most of these studies have looked at difficulties students encounter in solving application of differential problems and not in solving application of integral problems. Furthermore, these studies worked with engineering students as their participants but this study worked with students who are not engineers. Thus, to build on these studies, we intend to explicitly examine students' understanding of the key steps that are generally involved in the process of solving related applications of integral problems. In particular, our study was guided by the following research questions: What difficulties do students' encounter in solving application of integral problems? What problem solving strategies can improve students' problem solving skills in solving application of integral problems?

\subsection{Theoretical Framework}

The study was guided by the works of Mathematical Problem-Solving theory (Polya, 1957). Polya (1957) in his book How to Solve Itpresented four strategies that can be used to help learners solve mathematical problems. The theory states the four principles that form the basis for problem solving namely:

i. Understanding the problem.

ii. Devising a plan.

iii. Carrying out the plan.

iv. Looking back.

Therefore, Mathematical Problem-Solving theory by Polya (1957) provided us with a special language to understand students' difficulties in solving applications of integral problems in a natural setting, hence necessary to use in exploring and explaining the problem of engaging with application of integral problems and concepts at tertiary level from understanding the problem to looking back.

\section{Methodology}

The descriptive case study design on exploring students' difficulties in solving applications of integral problems in selected tertiary institutions of learning in Zambia was accomplished through a qualitative approach. Data was gathered using semi-structured interview. Semi-structured interviews are also a useful means of exploring someone else's ideas or thinking (Merriam, 1998). Scholars across the globe contends that interviews are said to be the best way to collect data because it helps researcher to have feelings, opinions, gestures, tone of voice, reactions, attitudes, views, and are useful in gathering in-depth data (Kvale, 1996), and this helped to enhance trustworthiness of these qualitative results (Meriam, 1998).Talking to the participants also helped us to have an in-depth 
understanding of students' difficulties in solving application of integral problems. Audio recordings were used to capture interviews in its totality. During analysis, data recorded from interviews were transcribed, edited, coded, categorized, and tabulated (Kothari and Garg, 2014).

\section{RESULTS AND DISCUSSION}

In this section, we present results and discussions on students' difficulties in solving applications of integral problems and to establish problem solving strategies that can improve students' skills in solving application of integral problems. Students have been coded as $\mathrm{A}_{1}$ to $\mathrm{A}_{50}$ (Students from institution $\mathrm{A}$ ), $\mathrm{B}_{1}$ to $\mathrm{B}_{50}$ (Students from institution $\mathrm{B}$ ), and $\mathrm{C}_{1}$ to $\mathrm{C}_{50}$ (Students from institution $\mathrm{C}$ ).

\subsection{Factors Constraining Students in Solving Application of Integral Problems}

The main student difficulties while trying to solve the integral problem:

"A metal disc has a radius of $5.0 \mathrm{~cm}$ and is of thickness $2.0 \mathrm{~cm}$. A semicircular groove of diameter $2.0 \mathrm{~cm}$ is machined centrally around the rim to form a pulley. Determine, using Pappus' theorem, the volume and mass of metal removed and the volume and mass of the pulley if the density of the metal is $8000 \mathrm{kgm}-3$ fell into the following two categories:

i. Difficulties related to understanding of the problem (language, use of the given information, identifying the variables); and

ii. Difficulties related to the identification and usage of the formula.

\subsection{Difficulties Related to the Identification and Usage of the Formula.}

Research findings indicates that students (129 out of 150) representing (86\%) reported having difficulties when identifying the formula to use as evidenced by the following typical verbatims:

"Couldn't figure out the formula to use in order to solve this problem" $\left(\mathbf{A}_{\mathbf{1}}\right)$.

"I had trouble with the units of the area of a semicircle, because in the given formula

I only knew the unit of volume of the metal removed which is $\mathrm{cm}^{3}$ " $\left(\mathbf{B}_{\mathbf{2}}\right)$.

"Could not see the connection between costs per hour and time" $\left(\mathbf{B}_{4}\right)$.

"Did not know where to use and compute $\frac{\pi r^{2}}{2}=\frac{\pi(1.0)^{2}}{2}=\frac{\pi}{2} \mathrm{~cm}^{2}$ "'( $\left.\mathbf{C}_{7}\right)$.

These students apparently understood the integral problem but could not use their existing mathematical knowledge of familiar formulae to set up the required function correctly.

The above difficulties encountered by students when solving application of integral problems are in agreement with the classification from the study by Anaya, Cavallaro, and Domingiez (2007) on novice engineering students' difficulties in mental processes doing a more general modelling task. These researchers found that the students in their study displayed:

i. Difficulties related to the relational understanding of the situation to be modelled, including difficulties in the identification of variables and unknowns.

ii. Difficulties related to creativity in establishing associations and relationships between pieces of knowledge that eventually might not have been related up to that moment.

iii. Difficulties related to the choice of the available knowledge and the use of the given information.

\subsection{Difficulties Related to Understanding of the Problem}

About (136 out of 150) students representing 91\% during the interviews responded that they had these difficulties when solving application of integral problems as evidenced by the following typical comments were as follows:

“The wording was ambiguous." $\left(\mathbf{A}_{\mathbf{3 0}}\right)$.

"I did not understand the question." $\left(\mathbf{B}_{2}\right)$.

"It was confusing." $\left(\mathbf{B}_{40}\right)$. 
"Hard to understand the problem." $\left(\mathbf{A}_{\mathbf{2 7}}\right)$.

"I thought it was too complicated." $\left(\mathbf{C}_{\mathbf{3 3}}\right)$.

"I had trouble when deciding on how to use the information." $\left(\mathbf{C}_{27}\right)$.

"I did not know how to convert the real-life problem into one to solve

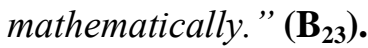

In the subsequent informal interviews with the selected students, it was revealed that the last comment was quite common. The fact that the answer was given hindered many students in their attempt to identify the unknown variable. The above difficulties are also consistent with the findings from a research study with upper secondary school students (Years 11 and 12) in Australia by Stillman (2004). By far the most frequently reported conditions impeding task access were: language problems related to technical language used in the context, comprehension difficulties, and the unusual wording of tasks.

\subsection{Student Perceptions of How to Improve their Skills in Solving Application of Integral Problems}

The researchers in this study took kin interest in finding out various perceptions amongst students on how to improve their skills in solving application of integral problems. The researchers in the subsequent subsections highlights on some of the ways of improving students' skills in solving application of integral problems.

\subsection{Regular Practice in Solving Application of Integral Problems}

In relation to regular practice in solving application of integral problems, majority of the students suggested that they needed more practice to improve their problem-solving skills. Thus, student $\mathrm{A}_{45}$ expressed that:

“.... More practice is in order to improve our problem-solving skills is the way to go. .... Practicing on daily basis is one effective way because calculus in general is not like topics like indices, trigonometry, set theory etc. Application of integral problems is heavily depended on practice and this practice is continued practices until we problem solvers attain a skill of solving.... So, we have to be practicing daily."

This is consistent with another study which was done by KlymchukandZverkova (2001)with more than 500 university students from 9 countries where the students also indicated that they felt it difficult to move from the real world to the mathematical world because of lack of practice in application tasks. It can be, therefore, argued that practice is certainly one of the ways that helps students to progress from novices to experts.

\subsection{Understanding the Language of the Application of Integral Questions}

Students during the interviews spoke passionately about the challenge posed by lack of understanding the language of the application of integral problems when solving integral problems. In trying to establish the inventory measures surmount to the challenges they encounter in solving calculus problems, learners however suggested that understanding the language of the application of integral problems before solving can improve their problem-solving skills. For instance, the following verbatim by student $\mathrm{B}_{9}$ act as a typical example:

“....... Majority of us students have difficulties when it comes to understanding the language of the application of integral problems. Thus, once we understand the grammar being used and have a culture of reading calculus problems before starting to solve calculus problems, we can improve in calculus sir."

Students' responses are in coherence with studies done by numerous researchers who have argued that familiarity with mathematical terminology improves problem-solving ability (Orton, 1983a) and contexts (Verschaffeland De Corte, 2000; Verschaffel et al., 1999). Clearly, we infer that understanding the language of the application of integral questions and mathematics knowledge are woven together, but further explorations with the application of integral questions that are not translation tasks are necessary. Consequently, if understanding the language of the application of 
integral questions influence students' ability to solve the application of integral problems then it might likely impact students' ability to solve application of integral problems.

\subsection{Collaborative Work}

Students spoke highly about solving application of integral problems with capable peers in order to improve their solving skills. The following verbatim are typical examples for student $B_{10}$ and $C_{4}$ :

“..........By solving different integral questions that involves application in real life, am certain our problem-solving skills can improve because through group work, we share ideas, we come up with means and ways of how to solve problems like integral" $\left(\mathbf{B}_{10}\right)$.

"Asking our friends and teachers to help us understand calculus concepts where we did not understand can be of help. In this way, our problem-solving skills when solving application of integral problems would improve" $\left(\mathbf{C}_{4}\right)$.

Respondents' responses conforms with different scholars who contended that collaborative work has been found to promote the use of higher-order thought processes, foster the use of academic problemsolving skills and perspective-taking skills, increase opportunities for oral rehearsal of information, and encourage and involve peers in learning which can increase friendship, acceptance, and cognitive processing skills (NCTM, 2014 and Kilpatrick et al., 2001).

Besides, literature has shown that, the challenges students encountered in solving calculus problems occurred because they did not have "More Knowledge" (Vygotsky, 1978) to help them learn integral problems that involve application to real life. As Vygotsky had argued, learning begins with an interaction in the social plan where students are passed on society's valued knowledge from previous generations to create a Zone of Proximal Development. Therefore, to improve students' problemsolving skills in solving the application of integral problems, it would be helpful if students solve integral problems that are applicable to real life situations with their peers.

\subsection{Understanding Application of Integral Formulas}

In an effort to address the challenges posed by incorrect citations of integral formulas for applicable problems, students suggested that in order to improve their problem-solving skills in solving application of integral problems, integral formulas need to be understood and applied appropriately. For instance, the following excerpts by students $\left(\mathrm{A}_{6}\right.$ and $\left.\mathrm{B}_{7}\right)$ acts as typical examples:

"Understand how to use calculus formulas sir" $\left(\mathbf{A}_{\mathbf{6}}\right)$.

“...... Know different calculus formulas and how to apply them” $\left(\mathbf{B}_{7}\right)$.

Studies by different scholars such as Kilpatrick et al., (2001) has shown that formulas in mathematics are key to finding answers. Besides, NCTM (2014) reported that mathematics is about knowing the formula or method to use on a particular problem and knowing how to solve that mathematical problem.

\section{CONCLUSION AND RECOMMENDATIONS}

The study explored difficulties students' encounter in solving application of integral problems and students' perception of how to improve their skills in solving application of integral problems. Students' problem solving in solving application of integral problems were constrained by a number of factors such as: difficulties related to the identification and usage of the formula and difficulties related to understanding of the problem. Results show that regular practice in solving application of integral problems, understanding the language of the application of integral questions, collaborative work, understanding application of integral formulas can improve students' problem-solving skills in solving application of integral problems.

Based on the study findings, the researchers have made the following recommendations:

i. Lecturers should be allocating more time on topics like the application of integral problems.

ii. Lecturers need to assign translation problems that cannot be solved by trivial syntactic or other non-operative approaches. 
iii. Lecturers should be demonstrating many examples the shortcomings of the latter methods.

iv. Lecturers should be emphasizing the operative nature of equations.

v. Lecturers should focus on the development of the formulas.

\section{REFERENCES}

[1] Anaya, M., Cavallaro, M. I., \&Domingiez, M. C. (2007). Modelling: Difficulties for novice engineering students. In C. Haines, P. Galbraith, W. Blum, \& S. Khan (Eds.), Mathematical Modelling (ICTMA 12): Education, Engineering and Economics (pp. 324-332). Chichester, UK: Horwood.

[2] Clement, J., Lochhead, J., \& Monk, G. (1981). Translation difficulties in learning mathematics. The American Mathematical Monthly,88(4), 286-290.

[3] Craig, T. (2002). Factors affecting students' perceptions of difficulty in calculus word problems. In I. Vakalis, D. H. Hallet, C. Kourouonoitis, D. Quinney, \& C. Tzanakis(Eds.), Proceedings of the Second International Conference on the Teaching of Mathematics at the Undergraduate Level - ICTM-2. Crete, Greece: Wiley, CD format, \#411.

[4] Crouch, R., \& Haines, C. (2004). Mathematical modelling: Transitions between the real world and the mathematical world. International Journal on Mathematics Education in Science and Technology, 35(2), 197-206.

[5] Galbraith, P., Stillman, G., Brown, J., \& Edwards, I. (2007). Facilitating middle secondary modelling competencies. In C. Haines, P. Galbraith, W. Blum, S. Khan (Eds.), Mathematical modelling (ICTMA 12): Education, engineering and economics (pp. 130-140). Chichester, UK: Horwood.

[6] Kilpatrick, J., Swafford, J., \&Findell, B. (2001). Adding it up: Helping children learn mathematics. Washington: National Academy Press.

[7] Klymchuk, S. S. \&Zverkova T. S. (2001). Role of mathematical modelling and applications in university service courses: An across countries study. In J. F. Matos, W. Blum, S. K. Houston, \& S. P. Carreira (Eds.) Modelling, applications and Mathematics Education - Trends and Issues (pp. 227-235). Chichester, UK: Ellis Horwood.

[8] Kothari, C. R \& Garg, G. (2014). Research methodology; Methods and Techniques. New Delhi: New Age International Publishers

[9] Kvale, S. (1996). Interviews: An introduction to qualitative research interviewing. Thousand Oaks, CA: Sage.

[10] MESVTEE (2013). Zambia Education Curriculum Framework, Ministry of Education. Lusaka: Curriculum Development Centre.

[11] MESVTEE (2013c). 'O’ Level Mathematics Syllabus, (Grades 10-12), Lusaka: Curriculum Development Centre.

[12] National Council of Teachers of Mathematics, (2014). Principles to actions: Ensuring mathematical success for all. Reston, VA: NCTM.

[13] Polya, G. (1957). How to solve it. Princeton, NJ: Princeton University Press.

[14] Orton, A. (1983a). Students' understanding of integration. Educational Studies in Mathematics, 14, 1-18.

[15] Stillman, G., Brown, J., \& Galbraith, P. (2008). Research into the teaching and learning of applications and modelling in Australasia. In H. Forgasz et al. (Eds.), Research in Mathematics Education in Australasia 2004-2007 (pp. 141-164). Rotterdam, The Netherlands: Sense Publishers.

[16] Verschaffel, L., De Corte, E., Lasure, S., Van Vaerenbergh, G., Bogaerts, H., \&Ratinckx, E. (1999). Learning to solve mathematical application problems: A design experiment with fifth graders. Mathematical Thinking and Learning, 1, 195-229.

[17] Verschaffel, L., Greer, B., \& De Corte, E. (2000). Making sense of word problems. Lisse, Netherlands: Swets\&Zeitlinger.

[18] Vygotsky, L. (1986). Thought and Language. Cambridge, MA: MIT Press.

[19] Zulu, J. (2019). Learner's Problem Solving Processes in Calculus at Grade 12 Level: A Case Study of Two Selected Secondary Schools in Lusaka District, Zambia. Masters Dissertation. The University of Zambia.

\section{AUTHORS' BIOGRAPHY}

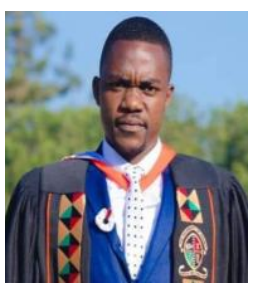

Julius Zulu, is a Mathematics at Rock view University in the School of Natural Science. He holds a Master of Science in Mathematics Education from the University of Zambia in Lusaka, Zambia. Mr. Zulu also holds a Master of Science in Mathematical Sciences from Rock view University in Lusaka, Zambia. He as well holds a Bachelor of Arts with Education degree (Mathematics Major with Geography Minor) from the University of Zambia, Lusaka, Zambia. Mr. Zulu is 
currently pursuing a Doctor of Philosophy in Mathematics Education from Atlantic International University from the United States of America. Mr. Zulu has been researching, publishing and teaching on issues such as; Mathematics, Mathematics Education, Educational Technology, Teacher Education and pedagogy.

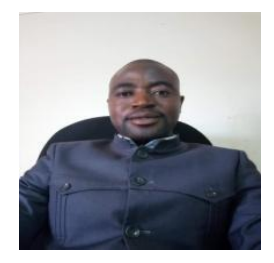

Robert Changwe, is a Curriculum and Teacher Education Scholar at the University of Zambia in the School of Education. He holds a Master of Education in Curriculum Studies from the University of Zambia in Lusaka, Zambia. He as well holds a Bachelor of Arts with Education degree rom the University of Zambia, Lusaka, Zambia and a Secondary School Teachers' diploma from Copperbelt Secondary Teachers' College, Kitwe, Zambia. Mr. Chang we has been researching, publishing and teaching on issues such as; Curriculum Development and Implementation, Educational Assessment, Teacher Education and pedagogy.

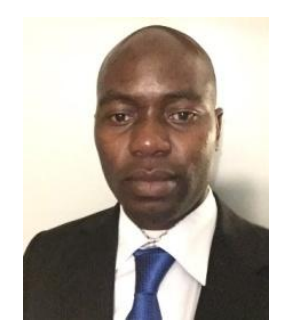

Nyimbili Friday, is a $\mathrm{Ph}$. D student at the University of Zambia, School of Education, department of Language and Social Science Education, proof reader and Part Time lecturer at Chalimbana University, Languages department.

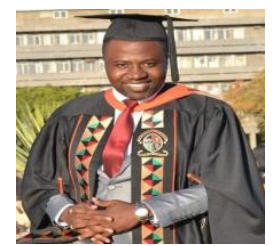

Fumbani Mphande, is an International Researcher, Lecturer, consultant, Teacher and Sociologist $\mathrm{He}$ is currently a Research Coordinator for all undergraduate Research Projects at Graduate School of Business at UNZA and part-time Lecturer for Industrial Sociology and Research Methods undergraduate. He is a Research Supervisor for Undergraduate at Graduate School of Business at University of Zambia. Fumbani has journals published in USA, Romania, Spain, Cyprus and one from Zambia. He is part-time Director of faculties at Central Hamburg University- Diversity Learning Institute in Germany .He was Head of Department, School of Education and Sociology at University of Africa. Fumbani was a Part-time Lecturer at University of Zambia in the Department of Educational Psychology, Sociology and Special Education. Fumbani is an academic product of University of Zambia;. Fumbani has passion in Lecturing, community works and has a niche in research supervision, publications and presenting papers at international research conferences.

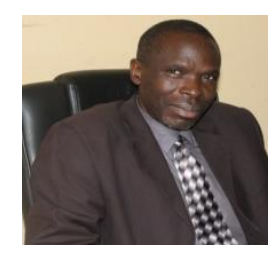

Donald Chisowa, speciality is Animal Science, at Institution of Rockview University in the Department of Agricultures, Zambia

Citation: Julius Zulu, et.al. "Exploring Students' Difficulties in Solving Application of Integral Problems in Selected Zambian Colleges of Education" International Journal of Humanities Social Sciences and Education (IJHSSE), vol 8, no. 9, 2021, pp. 11-18. doi: https://doi.org/10.20431/2349-0381.0809002.

Copyright: (C) 2021 Authors. This is an open-access article distributed under the terms of the Creative Commons Attribution License, which permits unrestricted use, distribution, and reproduction in any medium, provided the original author and source are credited. 